\title{
Effects of normal aging on obstruents' acoustic characteristics
}

Eirini Papadiamantopoulou ${ }^{1}$, Elina Nirgianaki ${ }^{2}$

${ }^{1}$ Department of Speech \& Language Therapy, Akmi Metropolitan College, Greece

${ }^{2}$ Lab of Phonetics \& Computational Linguistics, University of Athens, Greece

https://doi.org/10.36505/ExLing-2015/06/0016/000253

\begin{abstract}
The present study constitutes an experimental investigation on adult female's temporal and spectral (formant transitions) parameters of Greek voiceless stop consonants $/ \mathrm{p}, \mathrm{t}$, $\mathrm{k} /$ and fricative consonant /s/, as functions of normal aging. The effects of place of articulation and syllabic structure on these acoustic parameters were also examined. Results indicated that the two age groups were only distinguished by the voice onset time (VOT) duration of the velar voiceless stop $/ \mathrm{k} /$ and by the $\mathrm{F} 2$ transition values after $/ \mathrm{p} /$ and $/ \mathrm{t} /$. A main effect of aging on fricative $/ \mathrm{s} /$ duration was not confirmed. In addition, VOT distinguished stops' place of articulation, and the factor of syllable structure was significant for $/ \mathrm{s} /$ duration.
\end{abstract}

Key words: aging, duration, formant transitions, Greek, voiceless obstruents

\section{Introduction}

The aging process causes anatomical and physiological changes in the speech production system, including laryngeal, respiratory, articulatory and resonance mechanisms (Vipperla, Renals and Frankel 2010).

Several studies have shown that the aging factor has a significant effect on formant frequencies (Xue and Xao 2003; Das et al 2012; Sfakianaki, n.d.). Additionally, it has been revealed that older speakers produce shorter VOTs when compared to younger groups (Torre and Barlow 2005; Yao, 2007). Aging has also been found to affect segmental duration in a proportional manner (Smith, Wasowicz and Preston, 1987; Brazeal, 1997; Nissen and Fox 2005; Yao 2007).

However, all these studies either examine the acoustic characteristics of sounds in other languages than Greek (e.g. Xue and Xao, 2003; Das et al 2012) or concern the comparison of sounds produced by children and those produced by adults (e.g. Sfakianaki, n.d.).

In this frame, the present study aims at investigating the aging effect on Greek adults in 1. VOT duration of voiceless stops, 2. fricative /s/ duration, and 3. post consonantal formant frequencies (F1, F2) after stops. Simultaneously, it examines: 1 . intragroup differences between VOT duration of stops, 2. the effect of syllable structure (/s, sk, ks/) on /s/ duration, and 3 . intragroup differences of $\mathrm{F} 1, \mathrm{~F} 2$ values after stops.

ExLing 2015: Proceedings of 6th Tutorial and Research Workshop on Experimental Linguistics, 26-27 June 2015, Athens, Greece 


\section{Methodology}

Ten female speakers were equally divided into two age groups: Group A, aged between 20-30, and Group B, aged between 60-70. Two-syllable words of CVCV and CCVCV structure, stressed on the first syllable were produced by both groups in three repetitions. The Greek words / para, 'tara, 'kara, 'sara, 'skara, 'ksara (nonsense)/were placed in the carrier sentence /i 'leksi ... 'ine elini'ci/ (The word ....is Greek).

Acoustic analysis was carried out in PRAAT (version 5.3.77). Both stops' Voice Onset Time (VOT) and fricative's duration measurements (in ms) involved the simultaneous consultation of waveform and wideband spectrogram. For the stop-vowel transitions, the formant loci for F1 and F2 $(\mathrm{Hz})$ were identified in reference to the spectrographic display as follows: 1. By the Praat-derived Formant Tracker, and 2. By numerical cursor readouts on the screen. Both F1 and F2 were calculated at vowel onset, at the first glottal pulse following stop offset. Statistical analysis was carried out in SPSS 17.0.

\section{Results}

Mean VOT durations of voiceless stops differed between the two groups, but ttests revealed significant difference only for $/ \mathrm{k} /[\mathrm{t}(28)=-4.449, \mathrm{p}<0.05]$, with older females producing longer VOT than younger ones (Fig.1). Moreover, place of articulation had a main effect on VOTs produced by the young group $[F(44)=85.663, \mathrm{p}<0.0001]$ with significant differences between $/ \mathrm{p} /-/ \mathrm{k} /$ and $/ \mathrm{t} /-/ \mathrm{k} /$; and by the older one $[\mathrm{F}(44)=122.763, \mathrm{p}<0.0001]$ with significant differences among all three places (Fig. 1).

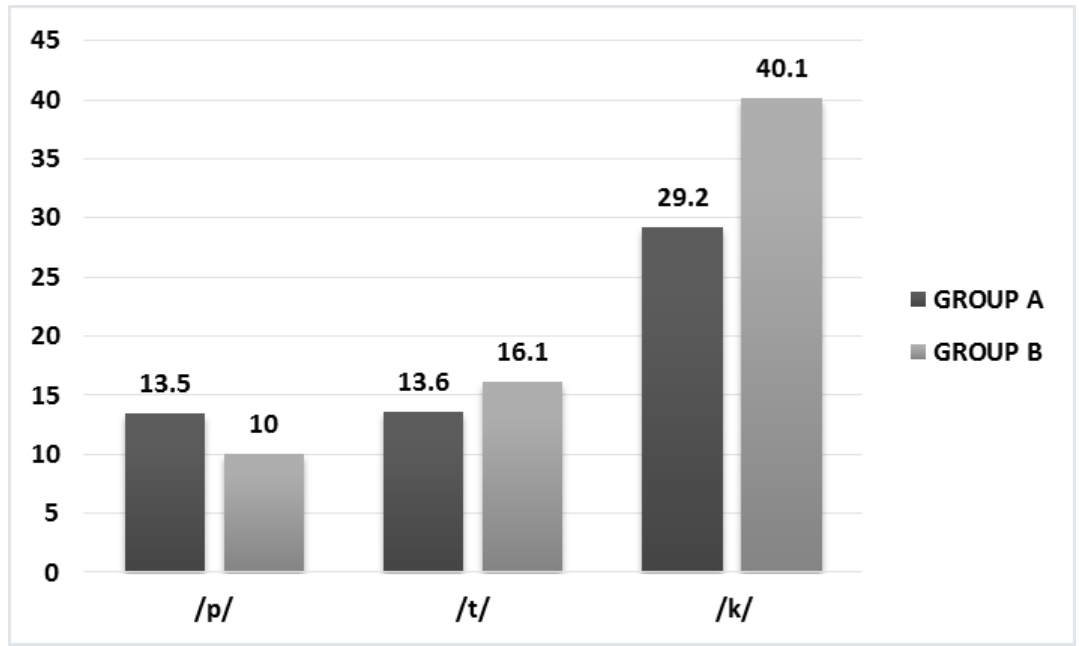

Figure 1. Mean VOT duration (ms) for $/ \mathrm{p} /, / \mathrm{t} /$, and $/ \mathrm{k} /$ as a factor of aging. 
Regarding / s/ duration, aging had no significant effect on it $[\mathrm{t}(28)=4.273$, $\mathrm{p}>0.05]$. Nonetheless, one way ANOVA showed that the syllable structure interacted significantly with fricative duration $[\mathrm{F}(89)=48.431, \mathrm{p}<0.0001]$. Absolute mean duration of $/ \mathrm{s} /$ for all speakers was longer when the sound was produced as singleton $(142 \mathrm{~ms})$, followed by /s/ in / ks/ $(110 \mathrm{~ms})$ and $/ \mathrm{s} /$ in /sk/ (107 ms).

Concerning formant transitions, there were no significant differences between age groups in F1. However, t-tests revealed significant differences in $\mathrm{F} 2$ after $/ \mathrm{p} /[\mathrm{t}(28)=0,798, \mathrm{p}<0.05]$, and $/ \mathrm{t} /[\mathrm{t}(28)=2.397, \mathrm{p}<0.05]$, with the younger group exhibiting higher values, but no significant differences after $/ \mathrm{k} /$ $[\mathrm{t}(28)=1.899, \mathrm{p}>0.05]$ (Table 1).

Place of articulation affected significantly $\mathrm{F} 1$ for both the young $[\mathrm{F}$ $(44)=5.587, \mathrm{p}<0.05]$ and the older $[\mathrm{F}(44)=5.274, \mathrm{p}<005]$ group. Post hoc tests revealed significant differences between F1 after /p/ and $/ \mathrm{t} /(\mathrm{p}<0.05)$ for the young group, and $/ \mathrm{p} /$ and $/ \mathrm{k} /$ for both groups $(\mathrm{p}<0.05)$, with $\mathrm{F} 1$ being highest after $/ \mathrm{p} /$. Similarly, significant differences were revealed for both groups [Group A: $\mathrm{F}(44)=77.883, \mathrm{p}<0.0001 ;$ Group B: $\mathrm{F}(44)=16.105, \mathrm{p}<0.0001]$ between $\mathrm{F} 2$ after $/ \mathrm{p} /$ and $/ \mathrm{t} /$, and $/ \mathrm{p} /$ and $/ \mathrm{k} /(\mathrm{p}<0.0001)$, with $\mathrm{F} 2$ being lowest after /p/ (Table 1).

Table 1. Mean F1 and F2 values ( Hz) for both age groups (A and B) after stop consonants.

\begin{tabular}{|c|c|c|c|c|}
\hline \hline \multirow{2}{*}{ Consonant } & \multicolumn{2}{|c|}{ F1 } & \multicolumn{2}{c|}{ F2 } \\
\cline { 2 - 5 } & A & B & A & B \\
\hline$/ \mathrm{p} /$ & 770 & 785 & 1445 & 1398 \\
\hline$/ \mathrm{t} /$ & 658 & 665 & 1869 & 1764 \\
\hline$/ \mathrm{k} /$ & 653 & 614 & 1844 & 1721 \\
\hline \hline
\end{tabular}

\section{Discussion}

To sum up, aging was revealed to affect significantly VOT duration of only the velar voiceless stop $/ \mathrm{k} /$, with older females producing longer VOT $(40 \mathrm{~ms})$ than younger ones $(29 \mathrm{~ms})$. These results agree with Brazeal (1997), who reported that older speakers produce longer VOT for $/ \mathrm{k} /$, and similar VOT for $/ \mathrm{t} /$ than younger ones, but disagree with Torre and Barlow (2005), and Yao (2007), who report shorter VOTs for the older participants. However, the present results show that the age factor does not affect the fricative /s/ duration, although Nissen and Fox (2005), who examined /s/'s durational differences between children and adults, revealed shorter durations for children.

Our results confirm the fact that VOT provides classification cues for voiceless stops' place of articulation, in accordance with Fourakis (1986), who reported long duration for $/ \mathrm{k} /$, medium for $/ \mathrm{t} /$ and short duration for $/ \mathrm{p} /$. It 
also confirms that /s/ as a singleton has shorter duration than in clusters (/sk/ $/ \mathrm{ks} /$ ), also reported by Botinis et al (1999).

With regards to formant transitions, both groups were found to exhibit similar mean F1 values after all voiceless stops, contrary to other research findings (Das et al 2012; Sfakianaki, n.d.). On the other hand, the age affected significantly F2 for bilabial and alveolar places of articulation, with the younger group exhibiting higher F2 frequencies when compared to the older group, in accordance with Das et al (2012), Sfakianaki (n.d.), and Xue and Xao (2003) who all have reported that $\mathrm{F} 2$ values decrease with aging.

In conclusion, it seems that there is a compensatory effect of aging on stop voiceless consonants, i.e. the bilabials and alveolars are distinguished by F2 onset, while velars by VOT duration.

\section{References}

Botinis, A., Fourakis and M., Prinou, I., 1999. Prosodic effects on segmental durations in Greek. Communication and Technology, EUROSPEECH 99, vol. 6, 2475-78, Budapest, Hungary.

Brazeal, V., 1997. The effect of aging on elderly Female voice onset time and segment duration. DEd. Oklahoma State University.

Das, B., Mandal, S., Mitra, P., Basu, A., 2012. Effect of aging on speech features and phoneme recognition: a study on Bengali voicing vowels. Int J Speech Technol. Springer Science+Business Media, LLC 2012.

Fourakis, M.. 1986. A Timing model for word-initial CV syllables in Modern Greek. J Acoust Soc Am 79, 1982-1986.

Nissen, S.L., Fox, R.A., 2005. Acoustic and spectral characteristics of young children's fricative productions:A developmental perspective. J. Acoust. Soc. Am 118(4).

Sfakianaki, N.D. Acoustic characteristics of Greek vowels produced by adults and children.

Smith., B.L., Wasowicz, J. and Preston, J., 1987. Temporal characteristics of the speech of normal elderly adults. J Speech Lang Hear Res (Abst).

Torre, P., Barlow, J.A., 2005. Age-related changes in acoustic characteristics of adult speech. J Commun Disord 42, pp. 324-333.

Vipperla, R., Renals, S. and Frankel, J., 2010. Ageing voices: The effect of changes in voice parameters on ASR performance. J Audio Speech Music Process.

Xue,S.A. and Hao, G.J.,2003.Changes in the human vocal tract due to aging and the acoustic correlates of speech production:a pilot study. J Speech Lang Hear Res (Abst).

Yao, Y., 2007. Closure duration and VOT of word-initial voiceless plosives in English in spontaneous connected speech, UC Berkeley Phonology Lab Annual Report. 